\title{
Rosiglitazone and Pioglitazone Alter Aromatase Kinetic Properties in Human Granulosa Cells
}

\author{
Takako Araki, ${ }^{1}$ Miroslava Varadinova, ${ }^{1}$ Michael Goldman, ${ }^{1}$ \\ Zev Rosenwaks, ${ }^{2}$ Leonid Poretsky, ${ }^{1}$ and Donna Seto-Young ${ }^{1}$ \\ ${ }^{1}$ Gerald J. Friedman Diabetes Institute and the Division of Endocrinology, Department of Medicine, \\ Beth Israel Medical Center and Albert Einstein College of Medicine, New York, NY 10003, USA \\ ${ }^{2}$ Ronald O. Perelman and Cohen Center for Reproductive Medicine and Infertility, Weill Medical College of Cornell University,
} New York, NY 10021, USA

Correspondence should be addressed to Donna Seto-Young, dyoung@chpnet.org

Received 22 July 2011; Accepted 15 September 2011

Academic Editor: Carolyn Komar

Copyright () 2011 Takako Araki et al. This is an open access article distributed under the Creative Commons Attribution License, which permits unrestricted use, distribution, and reproduction in any medium, provided the original work is properly cited.

\begin{abstract}
We have previously reported that, in human granulosa cells, thiazolidinediones rosiglitazone and pioglitazone inhibit estrogen synthesis by interfering with androgen binding to aromatase, without an effect on aromatase mRNA or protein expression. In the current paper, we explore the effects of rosiglitazone and pioglitazone on the aromatase enzyme kinetic properties in human granulosa cells. The cells were incubated with various concentrations of testosterone or androstenedione, with or without rosiglitazone or pioglitazone. Estradiol and estrone concentrations in the conditioned tissue culture medium were measured by radioimmunoassay or immunosorbent assay. When testosterone was used as substrate, rosiglitazone or pioglitazone inhibited the $V_{\max }$ by $35 \%$ $(P<0.001)$ and $24 \%(P<0.001)$, respectively. When androstenedione was used as substrate, both rosiglitazone or pioglitazone inhibited $V_{\max }$ by $13 \%(P<0.007)$. We conclude that rosiglitazone or pioglitazone has no effect on $K_{m}$ but inhibits $V_{\max }$ of aromatase in human granulosa cells, therefore, acting as noncompetitive inhibitors.
\end{abstract}

\section{Introduction}

Thiazolidinediones (TZDs: troglitazone, rosiglitazone, and pioglitazone) are peroxisome proliferator-activated receptor$\gamma($ PPAR- $\gamma$ ) agonists, which have been used in the treatment of type 2 diabetes as insulin sensitizers. TZDs have also been used as therapeutic agents for women with polycystic ovary syndrome (PCOS) since they reduce androgen levels and improve ovulatory rates [1-4]. Although the effects of TZDs in the female reproductive system have been attributed to their systemic insulin-sensitizing properties and consequent reduction in hyperinsulinemia [5], TZDs also directly affect androgen and estrogen production in human ovarian cells [6].

Aromatase is a cytochrome P450 superfamily enzyme that converts androgens to estrogens. The literature on the TZD effects on aromatase activity in the ovary is controversial [7-9]. Our previous studies demonstrated that rosiglitazone or pioglitazone directly inhibit estrogen synthesis in the mixed human ovarian cell culture containing stromal, thecal, and granulosa cells and in purified human granulosa cells obtained from in vitro fertilization $[6,10]$. We recently reported that rosiglitazone or pioglitazone also interfere with androgen binding to aromatase enzyme, suggesting that TZDs may affect the aromatase enzyme kinetic properties [10].

The goal of this study, therefore, was to examine the effects of TZDs on the enzyme kinetic properties of aromatase.

\section{Materials and Methods}

The institutional review boards at the Beth Israel Medical Center and the Weill Medical College of Cornel University approved all studies described in this paper.

2.1. Human Granulosa Cells and Cell Culture. Human granulosa cells obtained during in vitro fertilization (IVF) were 
pooled from several patients at a time to ensure adequate cell number for the experiments. Diagnoses included male factor, tubal factor, and uterine factor infertility, endometriosis, or anovulation [10]. Human granulosa cells obtained during in vitro fertilization were purified on the Percoll gradients (50\% Percoll/Hank's balanced salt solution) as previously described [10]. Purified human granulosa cells were counted using hemocytometer, and $1 \mathrm{~mL}$ of $0.5 \times 10^{5}$ cells $/ \mathrm{mL}$ suspension was placed in 24 well tissue culture plates [10]. The cells were cultured for 48 hours at $37^{\circ} \mathrm{C}, 5 \% \mathrm{CO}_{2}, 90 \%$ humidity in M199 medium supplemented with $10 \%$ FBS, $10 \mu \mathrm{g} / \mathrm{mL}$ gentamicin, and $250 \mathrm{ng} / \mathrm{mL}$ amphotericin B. After 48 hours of incubation, the medium supplemented with $10 \%$ FBS was replaced by a medium with $2 \%$ FBS, in which the cells were incubated for additional $24 \mathrm{~h}$ before the kinetic experiments were performed.

2.2. Enzyme Kinetic Studies. For the aromatase enzyme kinetic studies, cells were incubated with various concentrations of testosterone $(0.025,0.05,0.1,0.133,0.25$, or $1.0 \mu \mathrm{M})$ or androstenedione $(0.025,0.05,0.1,0.133,0.25,0.5$, or $1.0 \mu \mathrm{M}$ ) for $150 \mathrm{~min}$, in the presence or absence of $25 \mu \mathrm{M}$ rosiglitazone or pioglitazone. The conditioned tissue culture medium was collected for determination of estrone and estradiol concentrations. Several time points $(150 \mathrm{~min}$, $240 \mathrm{~min}, 360 \mathrm{~min}$, and $720 \mathrm{~min}$ ) were included in the kinetic experiments. The velocity of aromatase activity ( $\mu \mathrm{M}$ estradiol $/ \mathrm{mg} / \mathrm{min}$ ) was $0.14,0.25,0.22$, and 0.28 , respectively, for the 150, 240, 360, and $720 \mathrm{~min}$ of the reaction time points. Because $150 \mathrm{~min}$ incubation time produced a linear reaction, this time point was chosen for the kinetic studies. The concentrations of the substrates were extended to those below and above the $K_{m}$.

2.3. Protein Measurement. Protein concentrations were determined by BCA (Bicinchoninic Acid Assay) [11].

2.4. Radioimmunoassay and Immunosorbent Assay. Estrone concentrations in the tissue culture medium were measured using enzyme-linked immunosorbent assay (ELISA). The cross-reactivity with estrone is $100 \%$, with estradiol $2.2 \%$, and with other related compounds $0.14 \%$. Estradiol concentration was measured using radioimmunoassay (RIA). The cross-reactivity with $17 \beta$-estradiol is $100 \%$ and with other related compounds less than $1 \%$.

2.5. Materials. M199 medium, heat-inactivated fetal bovine serum (FBS), gentamicin, and amphotericin were obtained from Invitrogen Corp., Carlsbad, CA, USA; testosterone and androstenedione were from Sigma-Aldrich Corp., St. Louis, Mo; rosiglitazone was from Cayman Chemical, Ann Arbor, Mich; pioglitazone was from Takeda Pharmaceuticals America, Inc. Lincolnshire, IL; Lowry protein assay kits were from Thermo Scientific, Rockford, IL, USA; estrone enzymelinked immuno-sorbent assay (ELISA) kits were from Alpco Diagnostics, Salem, NH; estradiol radioimmunoassay (RIA) kits were from the Diagnostic Systems Laboratories, Webster, TX, USA.
2.6. Statistical Analysis. All experiments were carried out in triplicates or quadruplicates and repeated 6 to 7 times. Two-way analysis of variance (ANOVA) was used to compare mean values according to substrate concentrations (testosterone or androstenedione) in the presence or absence of rosiglitazone or pioglitazone. The statistical interactions between the sets of data obtained with or without rosiglitazone or pioglitazone were examined. Pairwise Bonferroni's adjusted contrasts were used to determine statistical significance.

\section{Results}

3.1. Testosterone as Substrate. When testosterone was used as substrate, aromatase $V_{\max }$ was reduced by $35 \%$ with rosiglitazone $(P<0.001)$ (Figures $1(\mathrm{a})$ and $1(\mathrm{~b}))$ and by $24 \%$ with pioglitazone $(P<0.001)$ (Figures $1(\mathrm{a})$ and $1(\mathrm{c}))$. The $K_{m}$ was not affected (Figure 1(d)).

3.2. Androstenedione as Substrate. When androstenedione was used as substrate, rosiglitazone inhibited $V_{\max }$ by $13 \%$ $(P<0.007)$ (Figures 2(a) and 2(b)). Pioglitazone also inhibited $V_{\max }$ by $13 \%(P<0.004)$ (Figures $2(\mathrm{a})$ and $\left.2(\mathrm{c})\right)$. Neither rosiglitazone nor pioglitazone had significant effect on $K_{m}$ of aromatase (Figure $2(\mathrm{~d})$ ).

\section{Discussion}

Aromatase is a cytochrome P450 superfamily enzyme that converts androgens to estrogens and is highly expressed in granulosa cells. It is a key enzyme for the development of sexual characteristics, and its function is important in the pathogenesis of various diseases, including breast cancer [12-14].

Conflicting reports have been published regarding the effects of TZDs on the expression and activity of aromatase in the ovary $[8,9,15]$. For example, Gasic et al. reported absence of troglitazone effects on the aromatase in porcine granulosa cells [15], while other studies reported that troglitazone/LG100268 induced suppression of enzymatic expression and activity of aromatase in human granulosa cells and in granulosa cell carcinoma cell lines $[8,9]$. In our previous studies, rosiglitazone or pioglitazone directly inhibited estrogen synthesis in human mixed ovarian cell culture containing stromal, thecal, and granulosa cells [6]. Recently we reported that the mechanism of rosiglitazone or pioglitazone effect on estrogen synthesis in cultured human granulosa cells does not involve any effects on either aromatase mRNA or protein expression [10]. In contrast, another thiazolidinedione, troglitazone, inhibited aromatase mRNA expression in our studies, which is consistent with the literature $[8,9]$. We also showed that rosiglitazone or pioglitazone inhibited androgen binding to aromatase [10].

In this study, we examined the effects of rosiglitazone or pioglitazone on aromatase enzyme kinetic properties. Rosiglitazone or pioglitazone inhibited $V_{\max }$ of aromatase without affecting the $K_{m}$, suggesting that rosiglitazone or pioglitazone inhibit aromatase enzyme in a noncompetitive manner (rosiglitazone or pioglitazone did not compete with 


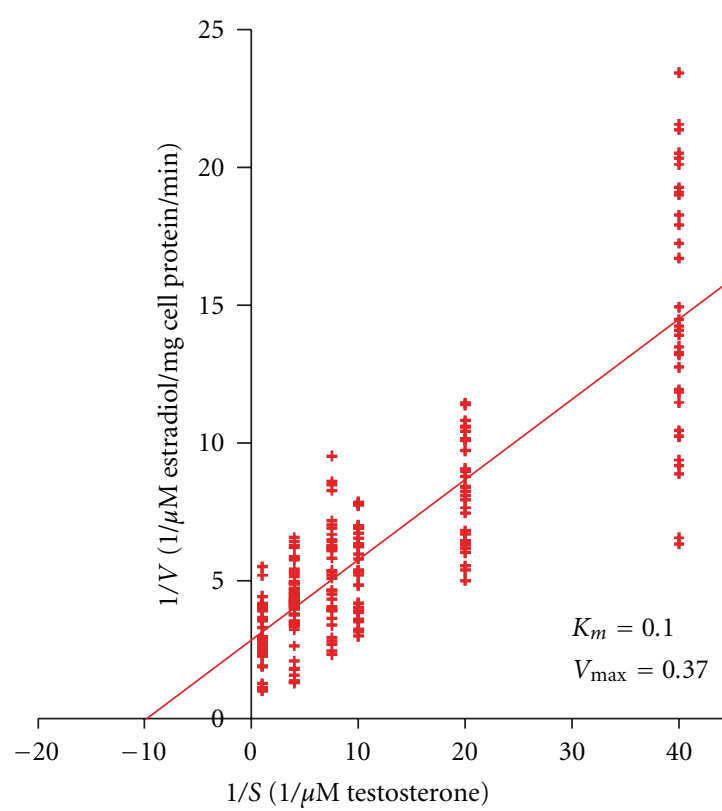

— Regression line (control)

(a)

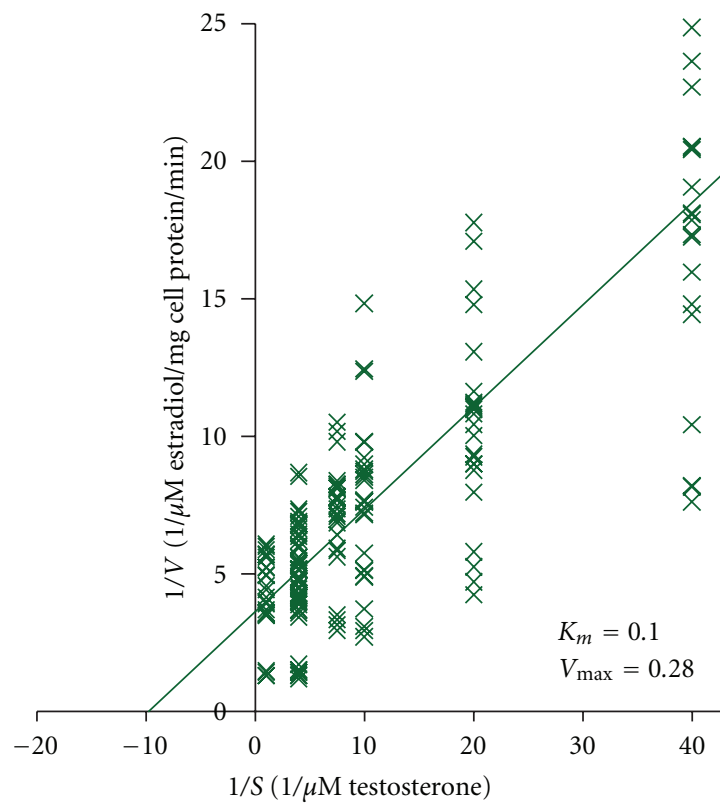

_ Regression line in the presence of $25 \mu \mathrm{M}$ pioglitazone

(c)

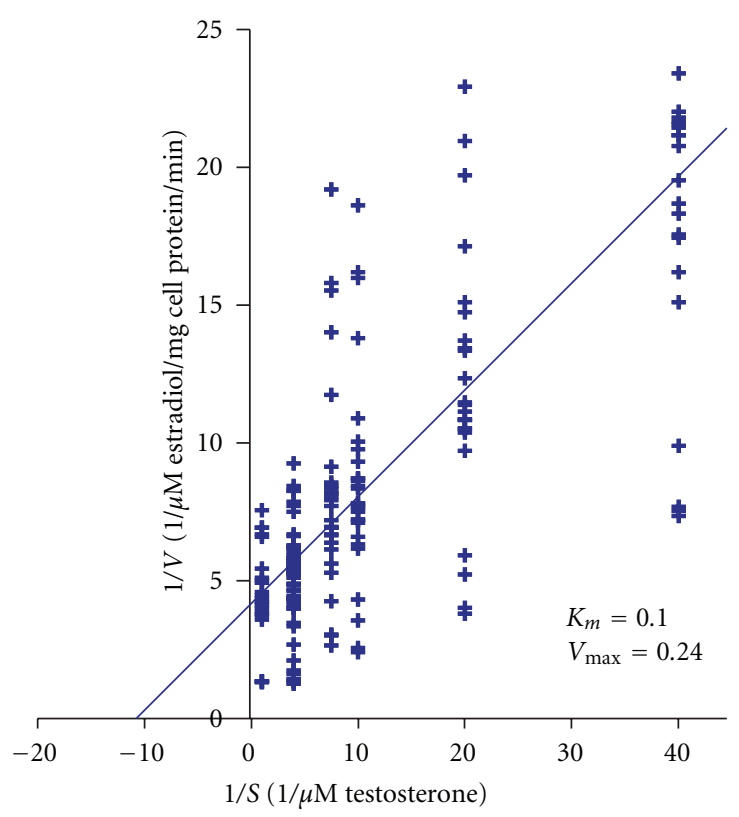

_ Regression line in the presence of $25 \mu \mathrm{M}$ rosiglitazone

(b)

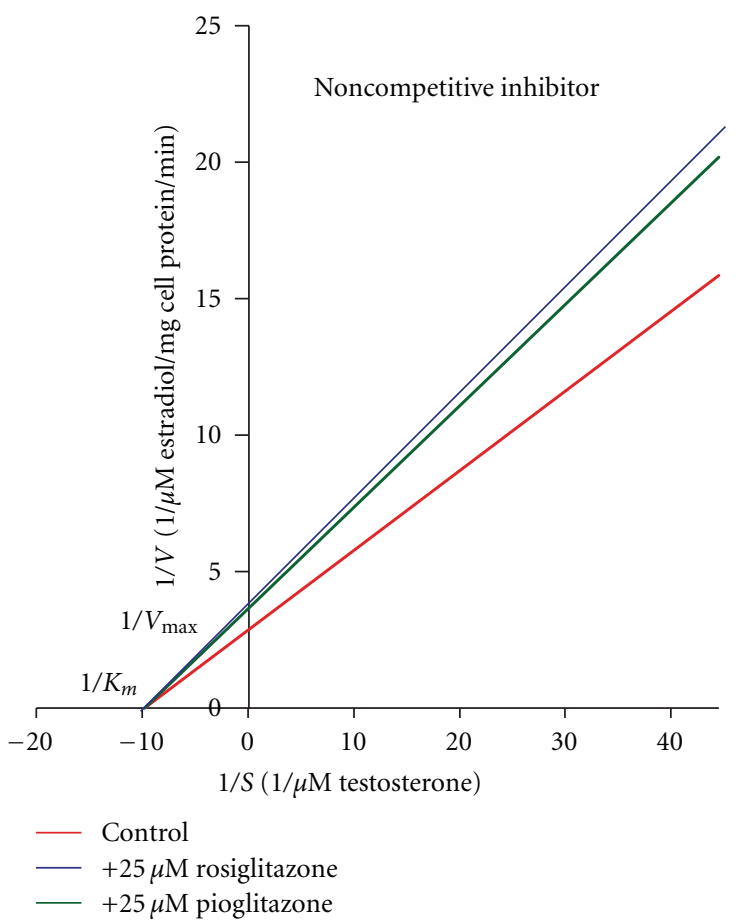

(d)

FIGURE 1: Effects of TZDs on aromatase enzyme kinetics when testosterone was used as substrate. (a) The Lineweaver-Burk plot (reciprocal velocities of aromatase activity against reciprocal testosterone concentration) in the absence of rosiglitazone or pioglitazone. (b) The Lineweaver-Burk plot in the presence of rosiglitazone. (c) The Lineweaver-Burk plot in the presence of pioglitazone. (d) Comparison of the Lineweaver-Burk plots in the presence or absence of rosiglitazone or pioglitazone. $V=$ velocity; $S=$ substrate.

substrate-testosterone or androstenedione-binding to aromatase). Our previous studies examined ${ }^{125}[\mathrm{I}]$-testosterone or ${ }^{125}[\mathrm{I}]$-androstenedione binding to immuno-purified aromatase bound to protein A immobilized on agarose [10].
Iodination of the substrates and procedure used for immunopurification of aromatase may have altered the substrate and enzyme structure in these studies. The current studies, which involved assessing initial activity rate of aromatase in 


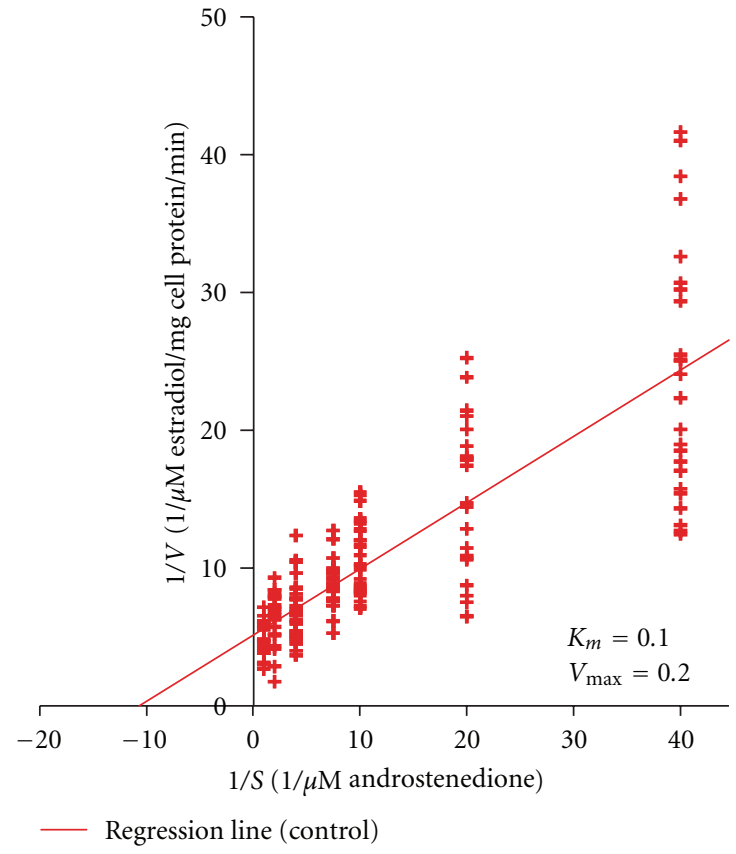

(a)

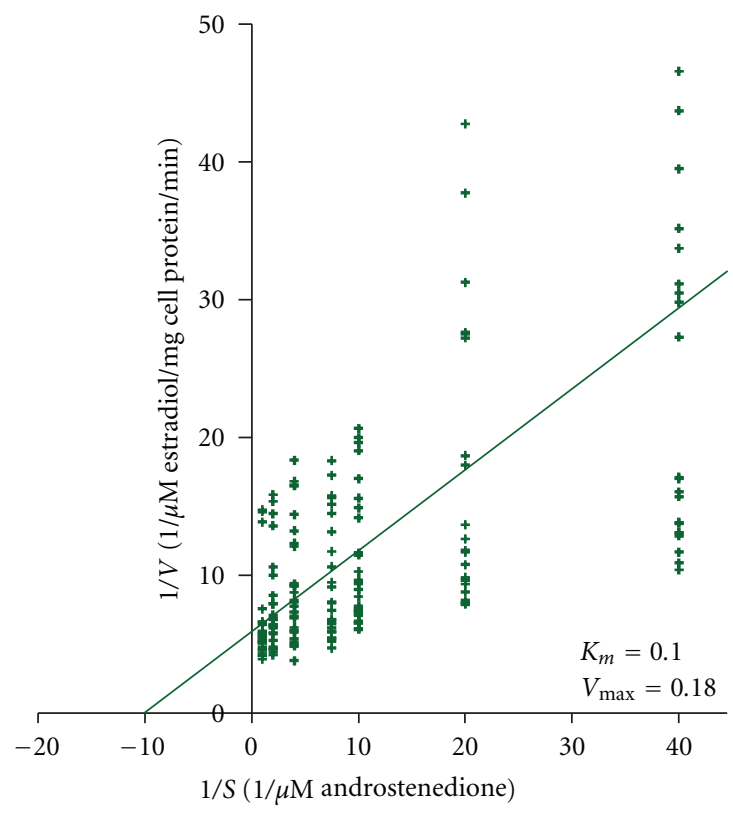

- Regression line in the presence of $25 \mu \mathrm{M}$ pioglitazone

(c)

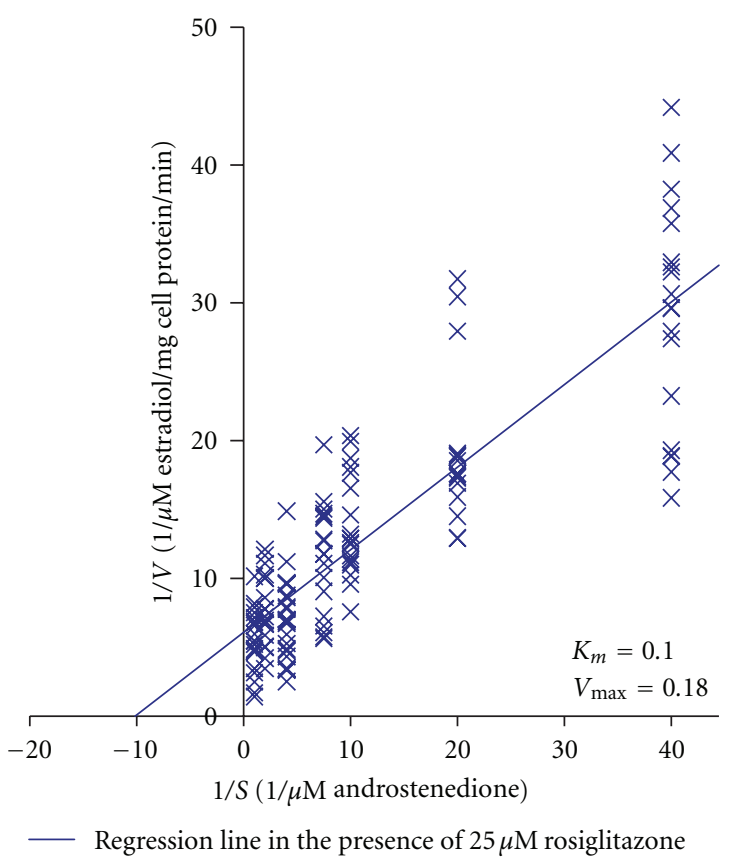

(b)

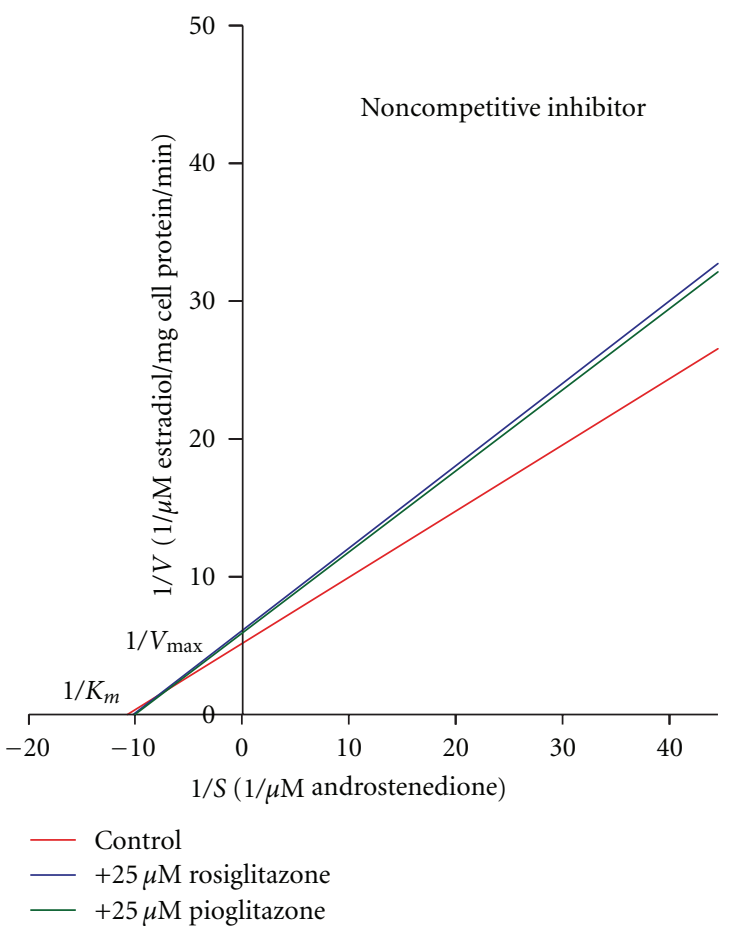

(d)

FIGURE 2: Effects of TZDs on aromatase enzyme kinetics when androstenedione was used as substrate. (a) The Lineweaver-Burk plot (reciprocal velocities of aromatase activity against reciprocal androstenedione concentration) in the absence of rosiglitazone or pioglitazone. (b) The Lineweaver-Burk plot in the presence of rosiglitazone. (c) The Lineweaver-Burk plot in the presence of pioglitazone. (d) Comparison of the Lineweaver-Burk plots in the presence or absence of rosiglitazone or pioglitazone. $V=$ velocity; $S=$ substrate.

the presence of various concentrations of substrates, allowed us to obtain more accurate Michaelis-Menten constants $K_{m}$ and $V_{\max }$.

The competitive aromatase inhibitors (anastrozole and letrozole) used in clinical practice to treat or to prevent breast cancer inhibit aromatase activity by $90-100 \%$. Rosiglitazone and pioglitazone, in contrast, inhibit aromatase activity by 30 to $50 \%$ [10]. The current studies show a $13-35 \%$ reduction in aromatase activity because the substrate concentrations were between 0.025 and $1 \mu \mathrm{M}$, which are either below or just above 
the $K_{m}$. In the previous studies, the substrate concentrations were above the $K_{m}(3 \mu \mathrm{M})$, and the incubation time was 18 hours.

This difference in potency may make thiazolidinediones an attractive alternative to competitive aromatase inhibitors because of presumably lower likelihood of aromatase-related side effects with TZDs (such as hot flushes and reduced bone density). In healthy postmenopausal women, annual bone loss associated with traditional aromatase inhibitors is higher than that observed with TZDs $(2.2-2.6 \%$ versus $0.5 \%$, resp.). Inhibition of estrogen synthesis by TZDs may make them useful in the therapy of estrogen-dependent diseases including breast cancer, gynecomastia, uterine fibroids, and endometrial cancer $[12,13]$. Inhibition of aromatase activity by TZDs may also help explain their negative effect on bone density in older or postmenopausal women [16, 17].

In conclusion, rosiglitazone or pioglitazone inhibits the aromatase enzyme activity by reducing its $V_{\max }$ without effect on $K_{m}$, acting as noncompetitive inhibitors of the aromatase enzyme.

\section{Disclosure}

T. Araki, M. Varadinova, M. Goldman, Z. Rosenwaks, L. Poretsky, D. Seto-Young have nothing to declare.

\section{Conflict of Interest}

None of the authors have a financial conflict of interest in regards to the materials included in this paper.

\section{Acknowledgments}

This work was supported in part by the Gerald J. R. Friedman Foundation, by the Empire Clinical Research Investigator Program of the New York State Department of Health, by the Chinese American Medical Society and Chinese American Independent Practice Association, and by the Yen Family Foundation.

\section{References}

[1] S. Dronavalli and D. A. Ehrmann, "Pharmacologic therapy of polycystic ovary syndrome," Clinical Obstetrics and Gynecology, vol. 50, no. 1, pp. 244-254, 2007.

[2] N. Brettenthaler, C. De Geyter, P. R. Huber, and U. Keller, "Effect of the insulin sensitizer pioglitazone on insulin resistance, hyperandrogenism, and ovulatory dysfunction in women with polycystic ovary syndrome," Journal of Clinical Endocrinology and Metabolism, vol. 89, no. 8, pp. 3835-3840, 2004.

[3] V.Sepilian and M. Nagamani, "Effects of rosiglitazone in obese women with polycystic ovary syndrome and severe insulin resistance," Journal of Clinical Endocrinology and Metabolism, vol. 90, no. 1, pp. 60-65, 2005.

[4] R. S. Legro, R. J. Zaino, L. M. Demers et al., "The effects of metformin and rosiglitazone, alone and in combination, on the ovary and endometrium in polycystic ovary syndrome," American Journal of Obstetrics and Gynecology, vol. 196, no. 4, pp. 402.e1-402.e11, 2007.

[5] L. Poretsky, N. A. Cataldo, Z. Rosenwaks, and L. C. Giudice, "The insulin-related ovarian regulatory system in health and disease," Endocrine Reviews, vol. 20, no. 4, pp. 535-582, 1999.

[6] D. Seto-Young, M. Paliou, J. Schlosser et al., "Direct thiazolidinedione action in the human ovary: insulin-independent and insulin-sensitizing effects on steroidogenesis and insulinlike growth factor binding protein-1 production," Journal of Clinical Endocrinology and Metabolism, vol. 90, no. 11, pp. 6099-6105, 2005.

[7] S. Gasic, Y. Bodenburg, M. Nagamani, A. Green, and R. J. Urban, "Troglitazone inhibits progesterone production in porcine granulosa cells," Endocrinology, vol. 139, no. 12, pp. 49624966, 1998.

[8] W. Fan, T. Yanase, H. Morinaga et al., "Activation of peroxisome proliferator-activated receptor- $\gamma$ and retinoid $X$ receptor inhibits aromatase transcription via nuclear factor- $\kappa \mathrm{B}$," Endocrinology, vol. 146, no. 1, pp. 85-92, 2005.

[9] Y. M. Mu, T. Yanase, Y. Nishi et al., "Insulin sensitizer, troglitazone, directly inhibits aromatase activity in human ovarian granulosa cells," Biochemical and Biophysical Research Communications, vol. 271, no. 3, pp. 710-713, 2000.

[10] D. Seto-Young, D. Avtanski, G. Parikh et al., "Rosiglitazone and pioglitazone inhibit estrogen synthesis in human granulosa cells by interfering with androgen binding to aromatase," Hormone and Metabolic Research, vol. 43, no. 4, pp. 250-256, 2011.

[11] K. J. Wiechelman, R. D. Braun, and J. D. Fitzpatrick, "Investigation of the bicinchoninic acid protein assay: identification of the groups responsible for color formation," Analytical Biochemistry, vol. 175, no. 1, pp. 231-237, 1988.

[12] G. L. Rubin, Y. Zhao, A. M. Kalus, and E. R. Simpson, "Peroxisome proliferator-activated receptor $\gamma$ ligands inhibit estrogen biosynthesis in human breast adipose tissue: possible implications for breast cancer therapy," Cancer Research, vol. 60, no. 6, pp. 1604-1608, 2000.

[13] Ö. Karaer, S. Oruç, and F. M. Koyuncu, "Aromatase inhibitors: possible future applications," Acta Obstetricia et Gynecologica Scandinavica, vol. 83, no. 8, pp. 699-706, 2004.

[14] T. Petit, P. Dufour, and I. Tannock, "A critical evaluation of the role of aromatase inhibitors as adjuvant therapy for postmenopausal women with breast cancer," Endocrine-Related Cancer, vol. 18, no. 3, pp. R79-R89, 2011.

[15] S. Gasic, M. Nagamani, A. Green, and R. J. Urban, "Troglitazone is a competitive inhibitor of $3 \beta$-hydroxysteroid dehydrogenase enzyme in the ovary," American Journal of Obstetrics and Gynecology, vol. 184, no. 4, pp. 575-579, 2001.

[16] A. V. Schwartz, D. E. Sellmeyer, E. Vittinghoff et al., "Thiazolidinedione use and bone loss in older diabetic adults," Journal of Clinical Endocrinology and Metabolism, vol. 91, no. 9, pp. 3349-3354, 2006.

[17] A. Grey, M. Bolland, G. Gamble et al., "The peroxisome proliferator-activated receptor- $\gamma$ agonist rosiglitazone decreases bone formation and bone mineral density in healthy postmenopausal women: a randomized, controlled trial," Journal of Clinical Endocrinology and Metabolism, vol. 92, no. 4, pp. 1305-1310, 2007. 


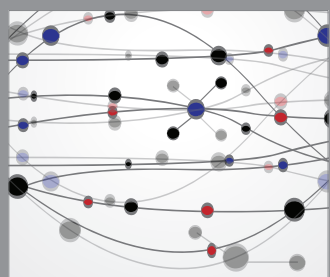

The Scientific World Journal
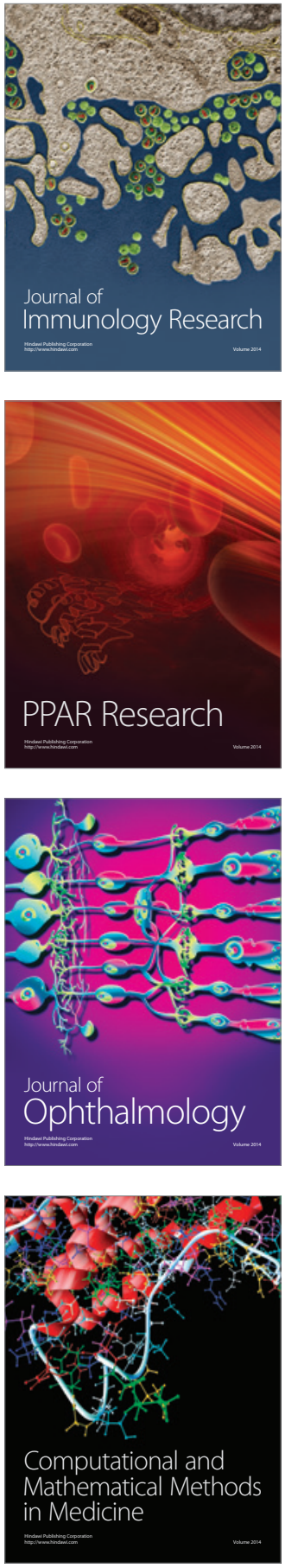

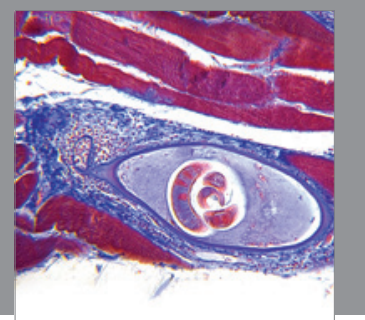

Gastroenterology

Research and Practice
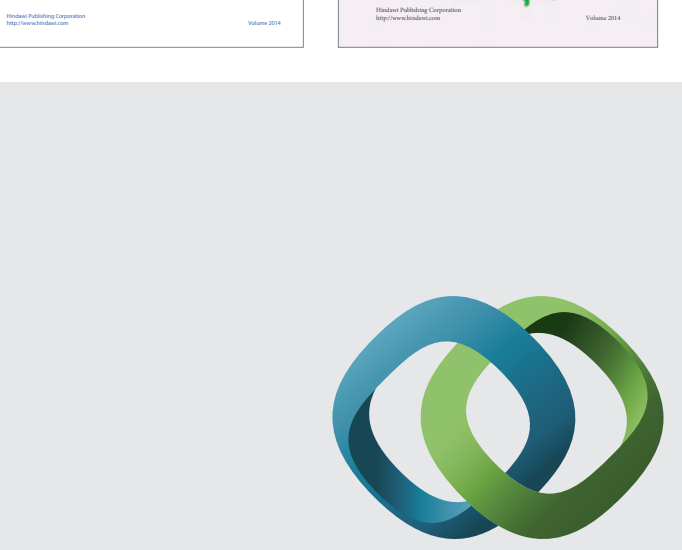

\section{Hindawi}

Submit your manuscripts at

http://www.hindawi.com
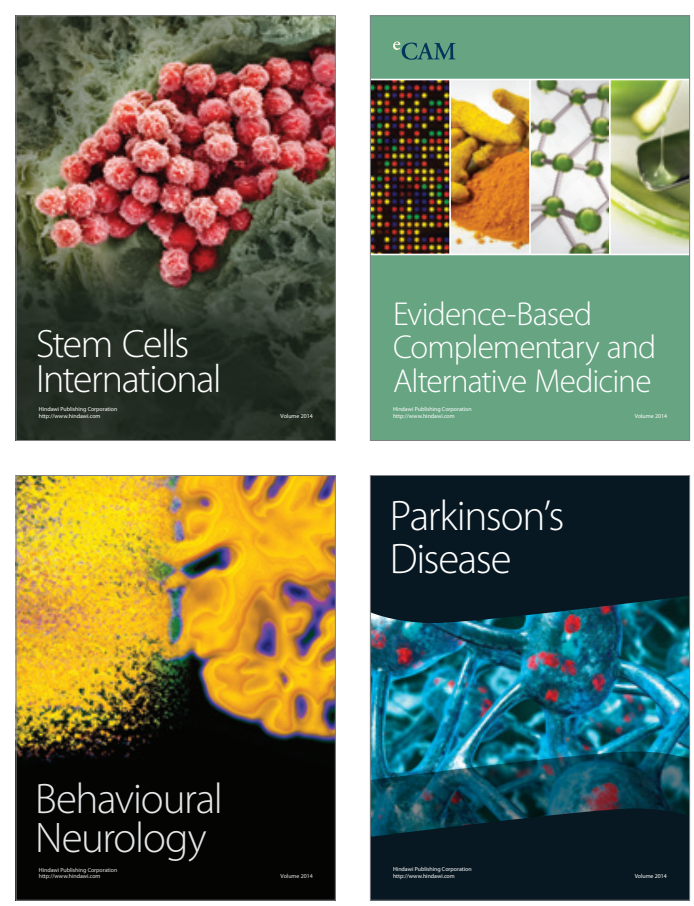

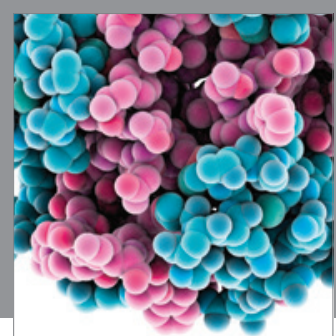

Journal of
Diabetes Research

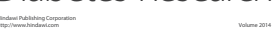

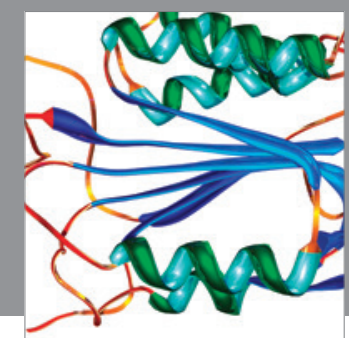

Disease Markers
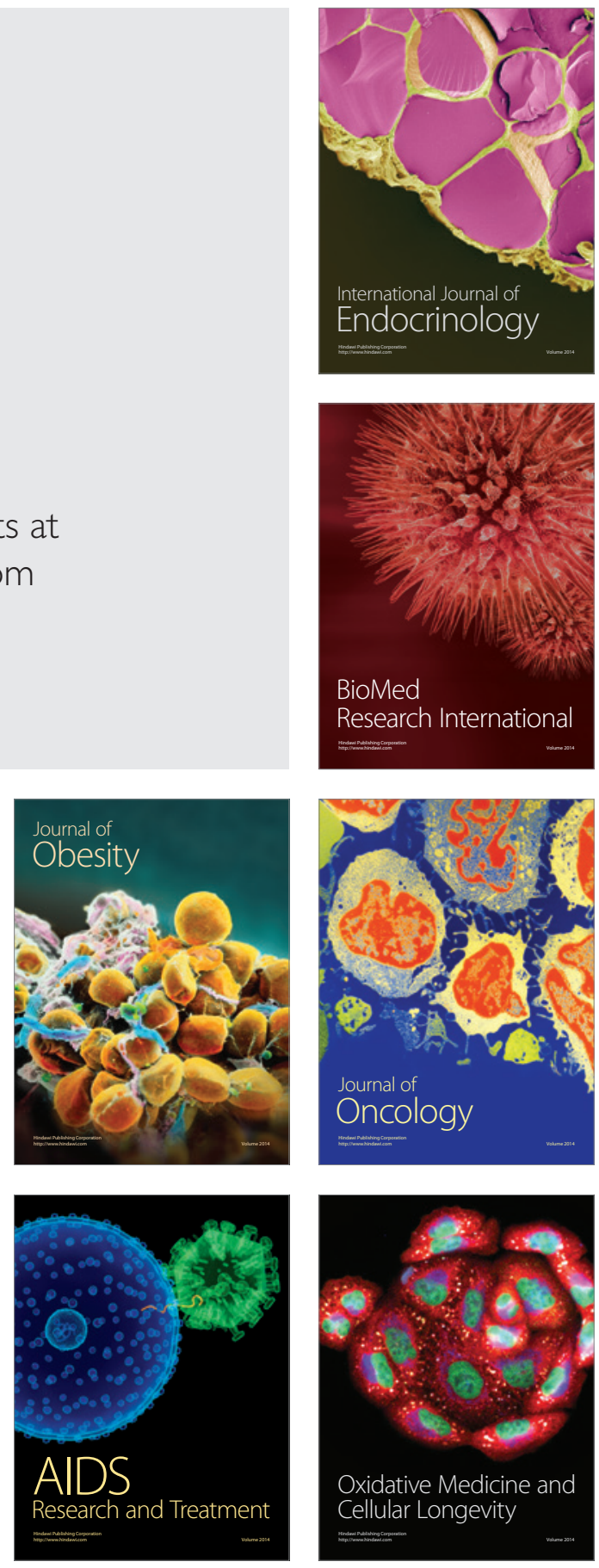